\title{
Three-dimensional print facilitated ventricular tachycardia ablation in patient with corrected congenital heart disease
}

\author{
Piotr Lodziński, Paweł Balsam, Michał Peller, Monika Gawałko, \\ Grzegorz Opolski, Marcin Grabowski \\ $1^{\text {st }}$ Department of Cardiology, Warsaw Medical University, Warsaw, Poland
}

Congenital heart disease is the most common type of birth defect causing significant hemodynamic and functional consequences, requiring surgical repair. An understanding of the precise surgical anatomy in such cases is often challenging and modern high resolution imaging techniques coupled with 3-dimensional (3D) printing may allow better visualization of the complex anatomy and improve planning of operations through hands-on simulation of surgical and interventional procedures [1-6].

A 52-year-old woman with a history of surgical treatment for tetralogy of Fallot (ToF), was referred to this department for ventricular tachycardia (VT) ablation. She had been treated in infancy with a left sided modified Blalock-Taussig shunt for ToF

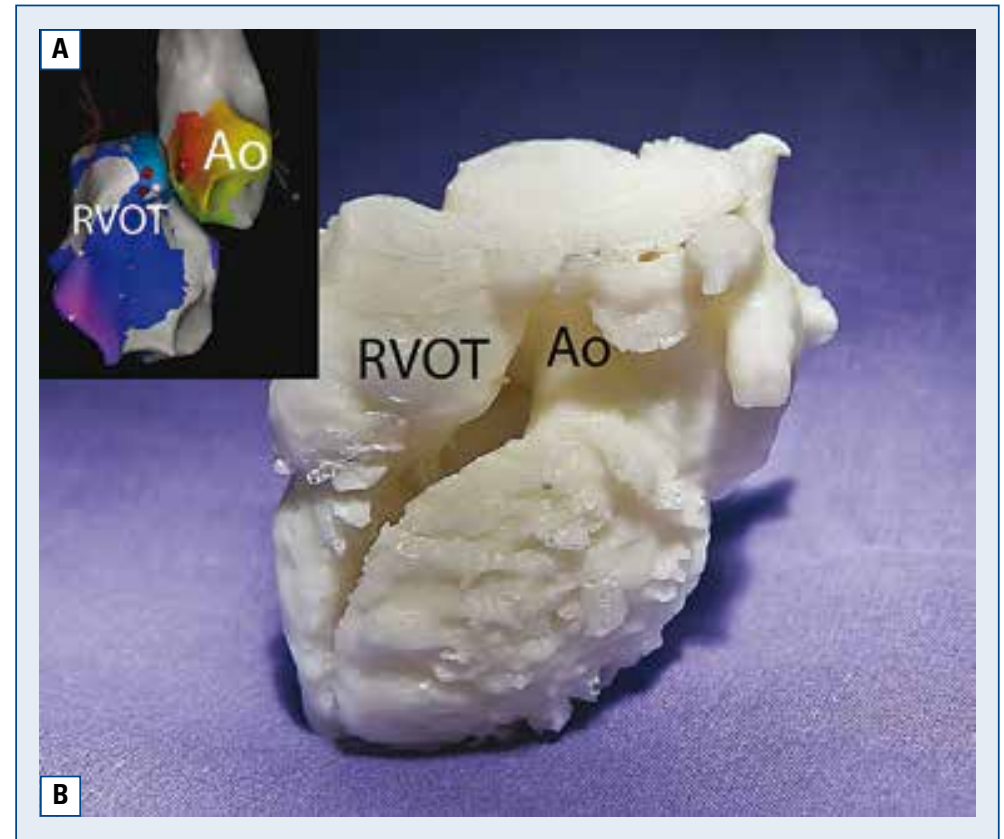

Figure 1. A. Left-lateral view from CARTO $3^{\circledast}$ electroanatomic system (red color indicates the earliest ventricular activation during ventricular tachycardia; purple dots indicate ablation sites); B. Left lateral view of three-dimensional printed model of the heart (size ratio 0.7 of original heart size); Ao - aorta; LVOT — left ventricular outflow tract; RVOT — right ventricular outflow tract.

Address for correspondence: Paweł Balsam, BA, MD, PhD, $1^{\text {st }}$ Department of Cardiology, Warsaw Medical University, ul. Banacha 1a, 02-097 Warszawa, Poland, tel: ++48 22599 19 58, fax: + +48 22 599-19-57, e-mail: pawel@balsam.com.pl Received: 09.05.2017 
and pulmonary atresia. At age 11, she had right ventricular outflow tract (RVOT) reconstruction using transannular incision that was extended from the main pulmonary artery bifurcation through the annulus and onto the right ventricle free wall for about $1-2 \mathrm{~cm}$, until the entire length of the infundibular septum was reached and augmented with a polytetrafluoroethylene (PTFE) patch. During the same year, she underwent ventricular septal defect closure with a 0.4-mm PTFE Gortex patch.

Tetralogy of Fallot correction is a complex cardiosurgical procedure. Cavity proportions, spatial orientation and catheter modified route were potential difficulties expected before the procedure. Moreover, pre-procedural computed tomography (CT) revealed a clock-wise rotation of the aortic bulb, causing the abnormal orientation of aortic sinuses, and origin of the right coronary artery in close vicinity of the RVOT. That's why, it was decided to print 3D-model of patient's heart not to make it possible but to compliment the procedure and enhance the operator's spatial orientation and have a better understanding of the aberrant anatomy and to plan the ablation procedure. The printed model was partially filled by scaffolding which unfortunately made it impossible to simulate catheter movements. It was also decided to print the model with 0.7 ratio of normal size to reduce printing time which lasted $11 \mathrm{~h}$ with prior multislice CT analysis for $2 \mathrm{~h}$.

During electrophysiological study, using CARTO 3 mapping system, the predominant morphology of VT was arising from the RVOT/left ventricular outflow tract. Single ablation was performed with a NaviStar Smart SF D-F catheter (Biosense Webster) in left Valsalva sinus which resulted in a permanent termination of the tachycardia (Fig. 1).

We herein present the first Polish case of 3D print facilitated ablation in patient with corrected congenital heart disease. 3D printed heart models and evaluation of a novel high resolution mapping technology $[7,8]$ may facilitate the ablation proce- dure in patients with a difficult anatomy, as well as in pediatric patients in whom catheter ablation is an increasingly used therapeutic strategy for the management of cardiac arrhythmias [9].

\section{Conflict of interest: None declared}

\section{References}

1. Kim MS, Hansgen AR, Carroll JD. Use of rapid prototyping in the care of patients with structural heart disease. Trends Cardiovasc Med. 2008; 18(6): 210-216, doi: 10.1016/j.tcm.2008.11.001, indexed in Pubmed: 19185811.

2. Riesenkampff E, Rietdorf U, Wolf I, et al. The practical clinical value of three-dimensional models of complex congenitally malformed hearts. J Thorac Cardiovasc Surg. 2009; 138(3): 571-580, doi: 10.1016/j.jtcvs.2009.03.011, indexed in Pubmed: 19698837.

3. Olivieri LJ, Krieger A, Loke YH, et al. Three-dimensional printing of intracardiac defects from three-dimensional echocardiographic images: feasibility and relative accuracy. J Am Soc Echocardiogr. 2015; 28(4): 392-397, doi: 10.1016/j.echo.2014.12.016, indexed in Pubmed: 25660668.

4. Valverde I, Gomez G, Gonzalez A, et al. Three-dimensional patient-specific cardiac model for surgical planning in Nikaidoh procedure. Cardiol Young. 2015; 25(4): 698-704, doi: 10.1017/ /S1047951114000742, indexed in Pubmed: 24809416.

5. Valverde I, Gomez G, Coserria JF, et al. 3D printed models for planning endovascular stenting in transverse aortic arch hypoplasia. Catheter Cardiovasc Interv. 2015; 85(6): 1006-1012, doi: 10.1002/ccd.25810, indexed in Pubmed: 25557983.

6. Biglino G, Capelli C, Wray Jo, et al. 3D-manufactured patientspecific models of congenital heart defects for communication in clinical practice: feasibility and acceptability. BMJ Open. 2015; 5(4): e007165, doi: 10.1136/bmjopen-2014-007165, indexed in Pubmed: 25933810.

7. Özkartal T, Müller-Burri SA, Brunckhorst CB, et al. Successful ablation of ventricular tachycardia with a novel multipolar highdensity mapping catheter. Cardiol J. 2016; 23(4): 446-448, doi: 10.5603/CJ.2016.0059, indexed in Pubmed: 27531493.

8. Di Toro D. Premature ventricular complexes ablation: A trip to the accuracy. Cardiol J. 2016; 23(1): 1-2, doi: 10.5603/ /CJ.2016.0012, indexed in Pubmed: 26927511.

9. Pietrzak R, Lodziński P, Książczyk T, et al. Pierwsze doświadczenia $\mathrm{w}$ zabiegach ablacji u dzieci w nowo powstałym pediatrycznym ośrodku elektrofizjologicznym. Kardiol Pol. 2017 Aug; [Epub ahead of print], doi: 10.5603/KP.a2017.0166. 